\title{
Safety and feasibility of prolonged versus early laparoscopic cholecystectomy for acute cholecystitis: a single-center retrospective study
}

\author{
Xing Cheng ${ }^{1} \cdot$ Ping Cheng ${ }^{1} \cdot$ Peng Xu ${ }^{1} \cdot$ Ping Hu${ }^{1} \cdot$ Gang Zhao $^{1} \cdot$ Kaixiong Tao $^{2} \cdot$ Guobin Wang $^{2} \cdot$ Xiaoming Shuai $^{2}$. \\ Jinxiang Zhang ${ }^{1}$
}

Received: 17 August 2019 / Accepted: 13 May 2020 / Published online: 22 May 2020

(c) The Author(s) 2020

\begin{abstract}
Background Laparoscopic cholecystectomy (LC) is the standard treatment for acute cholecystitis (AC), and it should be performed within $72 \mathrm{~h}$ of symptoms onset if possible. In many undesired situations, LC was performed beyond the golden $72 \mathrm{~h}$. However, the safety and feasibility of prolonged LC (i.e., performed more than $72 \mathrm{~h}$ after symptoms onset) are largely unknown, and therefore were investigated in this study.

Methods We retrospectively enrolled the adult patients who were diagnosed as AC and were treated with LC at the same admission between January 2015 and October 2018 in an emergency department of a tertiary academic medical center in China. The primary outcome was the rate and severity of adverse events, while the secondary outcomes were length of hospital stay and costs.

Results Among the 104 qualified patients, 70 (67.3\%) underwent prolonged LC and $34(32.7 \%)$ underwent early LC $(<72 \mathrm{~h}$ of symptom onset). There were no differences between the two groups in mortality rate (none for both), conversion rates (prolonged LC 5.4\%, and early LC 8.8\%, $P=0.68$ ), intraoperative and postoperative complications (prolonged LC 5.7\% and early LC $2.9 \%, P \geq 0.99$ ), operation time (prolonged LC $193.5 \mathrm{~min}$ and early LC $198.0 \mathrm{~min}, P=0.81$ ), and operation costs (prolonged LC 8,700 Yuan, and early LC 8,500 Yuan, $P=0.86$ ). However, the prolonged LC was associated with longer postoperative hospitalization ( 7.0 days versus 6.0 days, $P=0.03$ ), longer total hospital stay (11.0 days versus 8.0 days, $P<0.01$ ), and subsequently higher total costs (40,400 Yuan versus 31,100 Yuan, $P<0.01)$.

Conclusions Prolonged LC is safe and feasible for patients with AC for having similar rates and severity of adverse events as early LC, but it is also associated with longer hospital stay and subsequently higher total cost.
\end{abstract}

Keywords $72 \mathrm{~h}$ of symptoms onset · Acute cholecystitis · Prolonged versus early laparoscopic cholecystectomy

Acute cholecystitis (AC) is a common acute abdominal disease for emergency admission and there is about $3-10 \%$

Xing Cheng and Ping Cheng are co-first authors.

Jinxiang Zhang

zhangjinxiang@hust.edu.cn

1 Department of Emergency Surgery, Union Hospital, Tongji Medical College, Huazhong University of Science \& Technology, Wuhan 430022, Hubei, People's Republic of China

2 Department of Gastrointestinal Surgery, Union Hospital, Tongji Medical College, Huazhong University of Science \& Technology, Wuhan 430022, Hubei, People's Republic of China of acute abdominal pain linked to AC [1]. Right upper abdominal pain is the most typical symptom [2]. Usually a standardized treatment of laparoscopic cholecystectomy (LC) would be recommended for patients with AC [3-6]. Most researches[7-12] supported that LC should be done within $72 \mathrm{~h}$ of symptoms onset, which was nominated as early LC, due to the lower conversion rate, less intraoperative and postoperative complications, shorter hospitalization, and smaller amount of cost. According to TG18 (Tokyo Guideline 2018) [4], a delayed LC (i.e., performed at least 6 weeks after initial conservative treatment) might be proposed for patients with $\mathrm{AC}$ who had the onset of symptoms more than $72 \mathrm{~h}$.

Actually, surgeons always encountered patients with symptoms as disgusting and recurrent abdominal pain 
lasting more than $72 \mathrm{~h}$. These patients denied readmission for a delayed LC persistently. In addition, in clinical practice, there also may be a sudden attack forcing to an unprepared LC or even open cholecystectomy during the waiting for a delayed LC [4]. Furthermore, the conservative treatment and the following surgical hospitalization mean higher cost and more time consuming on the treatment of AC $[13,14]$. Therefore, researches on the safety and feasibility of prolonged LC are needed. A previous randomized clinical trial analyzed prolonged and delayed LC and found that prolonged LC was safe and associated with less overall morbidity, shorter hospital stay, and less cost compared with delayed LC [15]. So, we would like to confirm the safety and feasibility of a prolonged LC conducted in patients with the onset of symptoms more than $72 \mathrm{~h}$.

\section{Patients and methods}

This study was approved by the ethics committee of Tongji medical college, Huazhong University of Science and Technology (Study Number 2019 S937).

\section{Patient selection}

This single-center, retrospective study was performed at a department of emergency surgery in a tertiary academic medical center. During January 2015 and October 2018, patients diagnosed with $\mathrm{AC}$ and treated with $\mathrm{LC}$ at the same admission were included. The diagnosis of AC met the TG2018 [4], patients with at least one of local symptom or sign (murphy's sign, right upper quadrant tenderness/ pain/mass), one systemic sign (fever, evaluated C-reactive protein, evaluated white blood cell count $\left(>18,000 \mathrm{~mm}^{3}\right)$ ), and a confirmatory imaging test (color doppler ultrasound, computed tomography, and/or magnetic resonance cholangiopancreatography). The imaging evidences included the presence of gallstones, thickened gallbladder wall, pericholecystic fluid, and/or sonographic Murphy's sign. All imaging examinations were carried out by trained radiologists. The cases with choledocholithiasis, pancreatitis, pregnancy, and patients under 18 years old were excluded.

\section{Basic characteristics}

Data about age, sex, history of abdominal surgery, current smoking and drink, and pathological diagnosis were collected. The intraoperative pathological findings of simple, phlegmonous, or gangrenous cholecystitis were recorded. Each patient was assessed within the $24 \mathrm{~h}$ of admission by Acute Physiology and Chronic Health Evaluation IV (APACHE IV), Modified Early Warning Score(MEWS), Charlson Comorbidity Index (CCI), American Society of
Anesthesiologists Physical Status Classification System (ASA-PS), Sequential Organ Failure Assessment(SOFA), quick Sequential Organ Failure Assessment (qSOFA), Systemic Inflammatory Response Syndrome(SIRS), Numerical Pain Rating Scale (NPRS), and the Barthel index of Activities of Daily Living (ADL).

\section{Operative outcomes}

The primary outcomes were the mortality rate, admitted to intensive care unit (ICU) more than $24 \mathrm{~h}$, conversion rate to open cholecystectomy (OC), intraoperative and postoperative complications including massive bleeding $(>500 \mathrm{ml})$ [16] during and/or after operation, wound infection, and biliary leakage. The secondary outcomes were the operation time, length of hospital stay, duration of postoperation hospitalization, surgical and total costs.

\section{Surgical procedure}

All operations were performed by a fixed emergency surgeon team with 2-4 years of experience on laparoscopic techniques. LC was carried out with typical four incisions operation method $[17,18]$, and another incision maybe rarely needed in some difficult cases. LC conversion to OC was decided by the surgeon team independently.

\section{Statistical analysis}

Data were analyzed with the Statistical Package for Social Science (SPSS), IBM, version 22.0. Continuous variables were described by mean ( \pm standard deviation, $S D)$, median (interquartile ranges, IQR), they were compared with Student's $t$ test and Mann-Whitney $U$ test. Categorical variables were presented as percentages, they were compared with Pearson's chi-square test and Fisher's exact test. $P<0.05$ was considered significant.

\section{Results}

A total of 135 patients were admitted with the diagnosis of $\mathrm{AC}$ and underwent LC, 31 cases were excluded because of 21 cases with choledocholithiasis, 9 with acute pancreatitis, 1 with baby, there were 104 patients finally enrolled. Among the 104 patients $70(67.3 \%)$ underwent prolonged LC, 34 (32.7\%) underwent early LC (Fig. 1). The median time from symptoms onset to LC was 9 days with a range of 4-35 days and 3 days with a range of 1-3 days in the prolonged and early group, respectively.

Patients in prolonged and early groups had similar basic characteristics in age, gender, current drink and smoking, and history of abdominal surgery. There were 


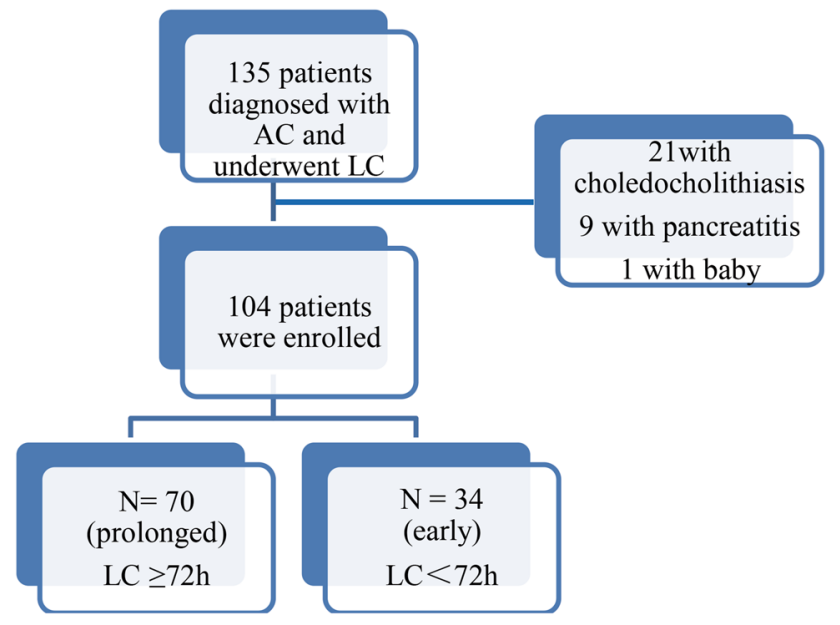

Fig. 1 Flow diagram of patients enrolled

no significant differences between the two groups on the assessment of APACHE IV, MEWS, CCI, ASA-PS, SOFA, qSOFA, SIRS, NPRS, and the Barthel index of ADL. In the prolonged group, patients presented with more serious classifications on TG18 $(P<0.01)$ though both groups had similar clinical (in surgery) and final pathological diagnosis $(P=0.95, P=0.37)$ (Table 1$)$. The overall morbidity of simple, phlegmonous, and gangrenous cholecystitis (Fig. 2) was $63.4 \%, 10.6 \%$, and $36.0 \%$. None died or admitted to intensive care unit (ICU) more than $24 \mathrm{~h}$ during the hospitalization. Both groups had similar conversion rate (prolonged LC 5.7\%, and early LC 8.8\%, $P=0.68$ ). We found that 4 patients losing blood more than $500 \mathrm{ml}$ during the operation in the prolonged group, and in the early group, 1 patient suffered from massive bleeding and wound infection. Though the prolonged group had higher intraoperative and postoperative complications than the early group (prolonged LC 5.7\%, early LC $2.9 \%$ ), there were no significant difference among them $(P \geq 0.99)$. The prolonged and early groups had similar operation time (prolonged LC $193.5 \mathrm{~min}$, and early LC $198.0 \mathrm{~min}$, $P=0.81$ ) and surgery costs (prolonged LC 8700 Yuan, and early LC 8500 Yuan, $P=0.86$ ), respectively. The total hospital stay and postoperation hospitalization were longer in the prolonged group ( 11.0 days versus 8.0 days, $P<0.01$ ) and (7.0 days versus 6.0 days, $P=0.03$ ). The prolonged group was also associated with higher total costs $(40,400$ Yuan versus 31,100 Yuan, $P<0.01$ ) (Table 2).

In Table 3, we analyzed the severe cholecystitis (grade III) which was classified on TG18. There were $6(8.6 \%)$ severe cases in the prolonged group, 2 (2.9\%) patients with renal dysfunction, 2 (2.9\%) with hepatic dysfunction, and $2(2.9 \%)$ with hematological dysfunction. And in the early group, 2 (5.9\%) patients classified to the severe AC owing to hematological dysfunction.
In this study, patients classified to moderate cholecystitis in prolonged and early groups were $64(91.4 \%)$ and 13 $(38.2 \%)$, respectively. Figure 3 showed that there were 14 (20.0\%) versus 10 (29.4\%) patients classified to moderate (grade II) AC associated with marked local inflammation in the prolonged and early groups, and $6(8.6 \%)$ versus $3(8.8 \%)$ patients simultaneously suffered from elevated WBC (white blood cell count) and marked local inflammation, respectively. Then, we analyzed patients classified to moderate (grade II) AC due to the onset of symptoms being more than $72 \mathrm{~h}$ with the mild (grade I) ones and further verified the safety and feasibility of prolonged LC.

Table 4 showed that the moderate and mild groups had similar basic characteristics on age, gender, current drink and smoking, and history of abdominal surgery, proportional scores on APACHE IV, MEWS, CCI, ASA-PS, SOFA, qSOFA, SIRS, NPRS, and the Barthel index of ADL assessed within $24 \mathrm{~h}$ of admission, clinical and final pathological diagnosis. The conversion from LC to OC and intraoperative and postoperative complications were similar ( 1 vs 0 patient) and ( 1 vs 0 patient), respectively. There were no significant differences in moderate and mild groups on operation time (moderate $177.0 \mathrm{~min}$, and mild $162.0 \mathrm{~min}$, $P=0.66$ ), duration of postoperation hospitalization (moderate 6.0 days, and mild 6.0 days, $P=0.26$ ), and operation costs (prolonged 7,800 Yuan, and mild 8,100 Yuan, $P=0.72)$. The moderate group had longer total hospital stay (10.0 days versus 8.0 days, $P<0.01)$ and higher total costs $(38,900$ Yuan versus 30,000 Yuan, $P<0.01)$.

\section{Discussion}

This retrospective study based on real clinical problem and confirmed the safety and feasibility of prolonged LC compared to early LC. Prolonged LC had not increased the conversion rate, intraoperative and postoperative complications, operation time, and cost. However, prolonged LC was associated with longer postoperation and total hospital stay and higher total cost compared to early LC. Our study indicated that early LC was superior to prolonged LC for patients with AC. It is particularly worth mentioning here that higher rate of prolonged LC was observed in our study (67.3\% VS 32.7\%), although early LC was recommended in clinical practice. We reviewed the medical records and found that most of the patients missed the golden $72 \mathrm{~h}$ when they went to see a doctor, and a few of them waited for the final diagnosis of AC. According to our results, for these patients, prolonged LC was recommended, rather than conservative treatment and waiting for a delayed LC.

There were many studies on the optimal time of surgery for AC. Numerous of evidence indicated that early LC is the first choice and secure when the duration of symptoms was 
Table 1 Baseline and clinical characteristics compared prolonged and early LC

\begin{tabular}{|c|c|c|c|}
\hline Characteristics & $\begin{array}{l}\text { Prolonged } \\
(n=70)\end{array}$ & $\begin{array}{l}\text { Early } \\
(n=34)\end{array}$ & $P$ value \\
\hline Age (years) $[$ mean $\pm S D]$ & $54.4(12.8)$ & $50.0(11.8)$ & 0.42 \\
\hline Gender $[n(\%)]$ & & & 0.16 \\
\hline Male & $35(50.0)$ & $22(64.7)$ & \\
\hline Female & $35(50.0)$ & $12(35.3)$ & \\
\hline Current drink $[n(\%)]$ & $4(5.7)$ & $3(8.8)$ & 0.68 \\
\hline Current smoking $[n(\%)]$ & $4(5.7)$ & $5(14.7)$ & 0.15 \\
\hline History of abdominal surgery $[n(\%)]$ & $12(17.1)$ & $2(5.9)$ & 0.14 \\
\hline APACHE IV [ median (IQR)] & $18.0(14.0-24.5)$ & $17.0(7.8-22.0)$ & 0.08 \\
\hline MEWS [ median (IQR)] & $4.0(3.0-5.0)$ & $4.0(4.0-5.0)$ & 0.09 \\
\hline CCI [ median (IQR)] & $3.0(2.0-5.0)$ & $2.5(1.0-4.0)$ & 0.13 \\
\hline ASA-PS $[n(\%)]$ & & & 0.24 \\
\hline I & $19(27.1)$ & 13(38.2) & \\
\hline II & $34(48.6)$ & $18(52.9)$ & \\
\hline III & $16(22.9)$ & $3(8.8)$ & \\
\hline IV & $1(1.4)$ & $0(0.0)$ & \\
\hline SOFA score [ median (IQR)] & $1.0(0.0-2.0)$ & $1.0(0.0-1.0)$ & 0.30 \\
\hline qSOFA scores $[n(\%)]$ & & & 0.56 \\
\hline 0 & $57(81.4)$ & $36(76.5)$ & \\
\hline 1 & $13(18.6)$ & $8(23.5)$ & \\
\hline SIRS criteria $[n(\%)]$ & & & 0.7 \\
\hline 0 & $23(32.9)$ & $7(20.6)$ & \\
\hline 1 & $24(34.3)$ & $12(35.3)$ & \\
\hline 2 & $15(21.4)$ & $10(29.4)$ & \\
\hline 3 & $5(7.1)$ & $3(8.8)$ & \\
\hline 4 & $3(4.3)$ & $2(5.9)$ & \\
\hline $\operatorname{NPRS}[n(\%)]$ & & & 0.59 \\
\hline 0 & $21(30.0)$ & $6(17.6)$ & \\
\hline 1 & $11(15.7)$ & $7(20.6)$ & \\
\hline 2 & $28(40.0)$ & $16(47.1)$ & \\
\hline 3 & $10(14.3)$ & $5(14.7)$ & \\
\hline The Barthel index of ADL $[n(\%)]$ & & & 0.15 \\
\hline $50-70$ & $24(34.3)$ & $6(17.6)$ & \\
\hline $75-95$ & $12(17.1)$ & $5(14.7)$ & \\
\hline 100 & 34 (48.6) & $23(67.6)$ & \\
\hline Severity grade of TG18 $[n(\%)]$ & & & $<0.01$ \\
\hline I (mild) & $0(0.0)$ & $19(55.9)$ & \\
\hline II (moderate) & $64(91.4)$ & $13(38.2)$ & \\
\hline III (severe) & $6(8.6)$ & $2(5.9)$ & \\
\hline Clinical pathological diagnosis $[n(\%)]$ & & & 0.95 \\
\hline Simple & $45(64.3)$ & $21(61.8)$ & \\
\hline Phlegmonous & $7(10.0)$ & $4(11.8)$ & \\
\hline Gangrenous & $18(25.7)$ & $9(26.5)$ & \\
\hline Pathological diagnosis $[n(\%)]$ & & & 0.37 \\
\hline Acute cholecystitis & $25(35.7)$ & $17(50.0)$ & \\
\hline Acute on chronic cholecystitis & $25(35.7)$ & $10(29.4)$ & \\
\hline Chronic cholecystitis & 20 (28.6) & $7(20.6)$ & \\
\hline
\end{tabular}

LC Laparoscopic Cholecystectomy, IQR Inter Quartile Range, APACHE IV Acute Physiology and Chronic Health Evaluation IV, MEWS Modified Early Warning Score, CCI Charlson Comorbidity Index, ASA-PS American Society of Anesthesiologists Physical Status Classification, SOFA Sequential Organ Failure Assessment, $q S O F A$ quick Sequential Organ Failure Assessment, SIRS Systemic Inflammatory Response Syndrome, NPRS Numerical Pain Rating Scale, ADL Activities of Daily Living, TG18 Tokyo Guideline 2018

Bold values are statistically significant difference with alpha of 0.05 

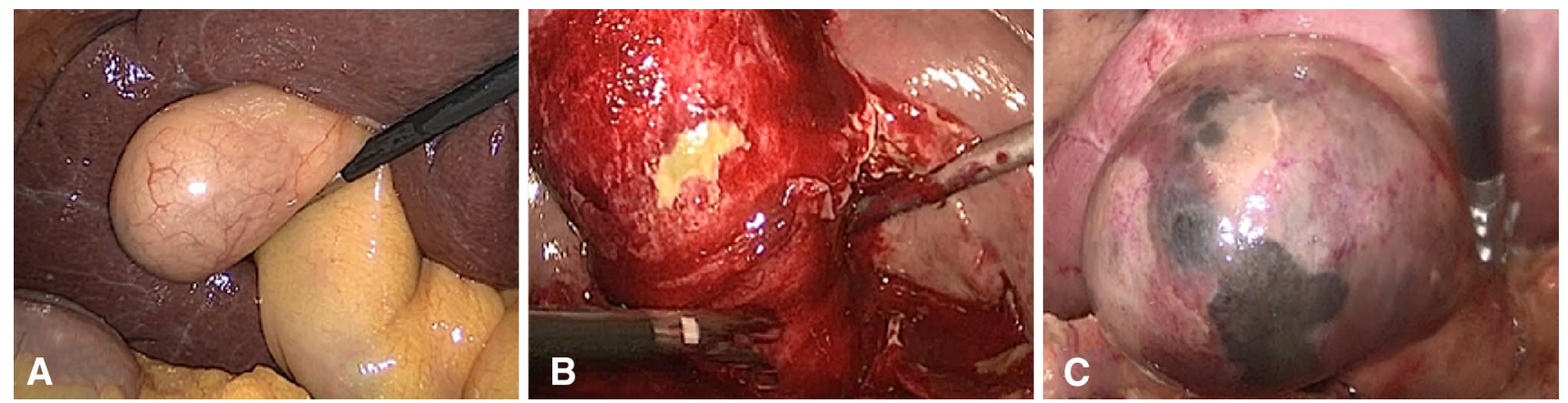

Fig. 2 Clinical pathological diagnosis of acute cholecystitis. A Simple cholecystitis, B phlegmonous cholecystitis, and $\mathbf{C}$ gangrenous cholecystitis

Table 2 Surgical characteristics and surgery-related outcomes

\begin{tabular}{|c|c|c|c|}
\hline Characteristics and Outcomes & $\begin{array}{l}\text { Prolonged } \\
(n=70)\end{array}$ & $\begin{array}{l}\text { Early } \\
(n=34)\end{array}$ & $P$ value \\
\hline Mortality $[n(\%)]$ & 0 & 0 & - \\
\hline $\mathrm{ICU}[n(\%)]$ & 0 & 0 & - \\
\hline Conversion rate $[n(\%)]$ & $4(5.7)$ & $3(8.8)$ & 0.68 \\
\hline No. patients with complications $[n(\%)]$ & $4(5.7)$ & $1(2.9)$ & 1.00 \\
\hline Bleeding $(>500 \mathrm{ml})$ & 4 & 1 & 1.00 \\
\hline Wound infection & 0 & 1 & \\
\hline Biliary leakage & 0 & 0 & \\
\hline Operative time (min) [median (IQR)] & $193.5(150.0-247.5)$ & $198.0(150.0-266.3)$ & 0.81 \\
\hline $\begin{array}{l}\text { Duration of postoperation hospitalization (days) [median } \\
\text { (IQR)] }\end{array}$ & $7.0(5.0-8.0)$ & $6.0(5.0-7.0)$ & $\mathbf{0 . 0 3}$ \\
\hline Total hospital length of stay (days) [median (IQR)] & $11.0(8.0-14.0)$ & $8.0(6.0-9.0)$ & $<0.01$ \\
\hline Cost for surgery (Yuan) [median (IQR)] & $8700(6500-12,000)$ & $8500(7100-11,800)$ & 0.86 \\
\hline Total cost of hospitalization (Yuan) [median (IQR)] & $40,400(33,900-51,100)$ & $31,100(24,900-37,000)$ & $<0.01$ \\
\hline
\end{tabular}

$I C U$ intensive care unit, $I Q R$ inter quartile range

Bold values are statistically significant difference with alpha of 0.05

Table 3 Evidences to patients classified to severe (grade III) cholecystitis on TG18

\begin{tabular}{lll}
\hline Evidences & $\begin{array}{l}\text { Prolonged } \\
(n=70)\end{array}$ & $\begin{array}{l}\text { Early } \\
(n=34)\end{array}$ \\
\hline Renal dysfunction & 2 & 0 \\
Hepatic dysfunction & 2 & 0 \\
Hematological dysfunction & 2 & 2 \\
\hline
\end{tabular}

TG18 Tokyo Guideline 2018

less than $72 \mathrm{~h}[4,8,19,20]$. And for those more than $72 \mathrm{~h}$, timely LC was better than delayed LC [15]. Another large, multicenter, prospective randomized clinical trial [21] compared early LC within $24 \mathrm{~h}$ of symptoms with delayed LC in 7-45 days of presentation, and confirmed that early LC should be performed for patients with AC. Thus, our study was complementary to these researches, for we defined the prolonged LC as patients with AC had LC beyond $72 \mathrm{~h}$ of symptoms onset and confirmed the safety and feasibility of prolonged $\mathrm{LC}$ for $\mathrm{AC}$.

Several studies $[21,22]$ have shown that early LC is superior to the delayed LC, but another real-world clinical study [23] indicated that a delayed LC is safe, and has better outcomes in morbidity and mortality. The opposite conclusions were probably derived from discrepant severity compositions of patients. In our study, we adopted several scoring systems to assess and standardize the responses of patients induced by the acute local or systemic inflammation at their admissions. The prolonged and early groups had equal scoring levels in each scoring system and it ensured the comparable preoperative states. Furthermore, both groups had similar clinical and final pathological diagnosis ranging from simple, phlegmonous, and gangrenous cholecystitis. There were also some really difficult 
Fig. 3 Evidences to patients classified to moderate cholecystitis in prolonged and early LC group on Tokyo Guideline 2018

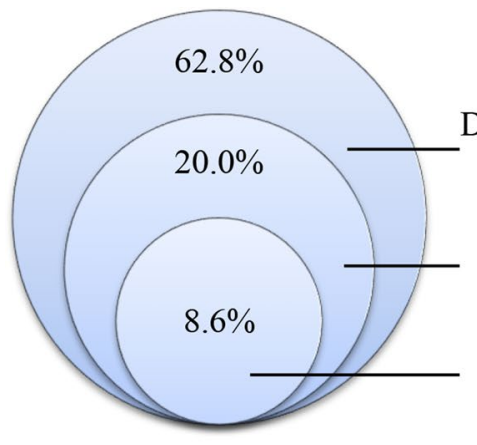

Prolonged LC

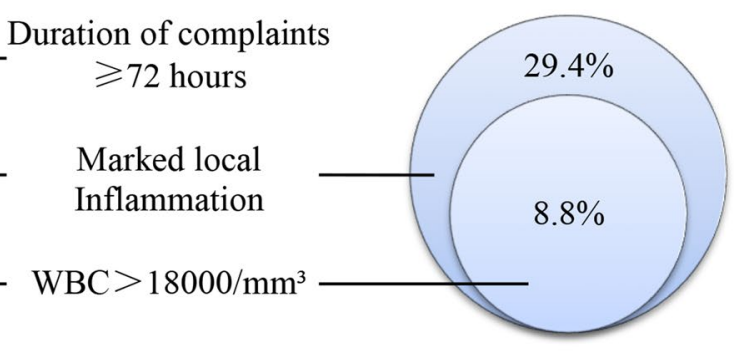

Early LC cases with severe gangrene or tight adhesion to surrounding tissues (Fig. 4), demonstrating that we included not just the 'easy' cases in our study. Therefore, the cases we enrolled in our study were good representation for the research target.

In this retrospective analysis, the overall morbidity of gangrenous cholecystitis (GC) was 27/104 (26.0\%), which was relatively high when compared to the reported morbidity of 5-26\% for GC [24-28], indicating that the patients with AC were really serious in our emergency department, which may also contribute to the longer overall operation time than that reported previously (195.0 $\mathrm{min}$ vs $88 \mathrm{~min}-116 \mathrm{~min})[15,29]$.

There were 8 patients classified to severe cholecystitis, 6 patients underwent prolonged LC, and 2 underwent early LC (Table 3). All of them recovered well at discharge. On the contrary, conservative management before a delayed LC was successful in only $60.6 \%$ of cases, $14.7 \%$ of patients required emergency surgery due to gangrene and/or perforation [30]. It indicated the removal of inflamed gallbladder as soon as possible might be preferable than a conservative intervention. Therefore, in some severe cases (grade III) with renal, hepatic, or hematological dysfunction, an aggressive early LC or prolonged LC could be performed with carefully assessment before the operation rather than a delayed LC.

There were similar percent of evidences (marked local inflammation, evaluated WBC) contributing to the classified to grade II (moderate) cholecystitis in the prolonged and early groups (Fig. 2), which indicated that evaluated WBC was concomitant to the local infection. And it might imply that the systemic immunological reactions resulted from the local inflammation in this study.

A limitation of this study was that patients were retrospectively admitted from emergency surgery department in a single center, and further prospective researches in multicenter were needed to be performed.

\section{Conclusion}

Prolonged LC for patients with AC was safe and feasible, and when patients with $\mathrm{AC}$ missed the golden $72 \mathrm{~h}$ for $\mathrm{LC}$, a prolonged $\mathrm{LC}$ could be recommended for them. 
Table 4 Basic characteristics and outcomes compared moderate cholecystitis only with symptoms more than $72 \mathrm{~h}$ with mild cholecystitis

\begin{tabular}{|c|c|c|c|}
\hline Characteristics & $\begin{array}{l}\text { Grade II (moderate) } \\
(n=44)\end{array}$ & $\begin{array}{l}\text { Grade I (mild) } \\
(n=19)\end{array}$ & $P$ value \\
\hline Age (years) $[$ mean $\pm S D]$ & $53.4(13.0)$ & $49.3(14.3)$ & 0.27 \\
\hline Gender $[n(\%)]$ & & & 0.11 \\
\hline Male & $18(40.9)$ & $12(63.2)$ & \\
\hline Female & $26(59.1)$ & $7(36.8)$ & \\
\hline Current drink $[n(\%)]$ & $3(6.8)$ & $2(10.5)$ & 0.63 \\
\hline Current smoking $[n(\%)]$ & $3(6.8)$ & $3(15.8)$ & 0.36 \\
\hline History of abdominal surgery $[n(\%)]$ & $10(22.7)$ & $1(5.3)$ & 0.15 \\
\hline APACHE IV [ median (IQR)] & $18.0(14.0-22.5)$ & $14.0(4.0-21.5)$ & 0.07 \\
\hline MEWS [ median (IQR)] & $4.0(3.0-5.0)$ & $4.0(4.0-4.5)$ & 0.57 \\
\hline CCI [ median (IQR)] & $3.0(2.0-4.5)$ & $2.0(0.0-4.0)$ & 0.21 \\
\hline ASA-PS $[n(\%)]$ & & & 0.24 \\
\hline I & $14(31.8)$ & $8(42.1)$ & \\
\hline II & $18(40.9)$ & $10(52.6)$ & \\
\hline III & $11(25.0)$ & $1(5.3)$ & \\
\hline IV & $1(2.3)$ & $0(0.0)$ & \\
\hline SOFA score [ median (IQR)] & $0.0(0.0-2.0)$ & $0.0(0.0-1.0)$ & 0.25 \\
\hline qSOFA scores $[n(\%)]$ & & & 0.49 \\
\hline 0 & $37(84.1)$ & $14(73.7)$ & \\
\hline 1 & $7(15.9)$ & $5(26.3)$ & \\
\hline SIRS criteria $[n(\%)]$ & & & 0.39 \\
\hline 0 & $17(38.6)$ & $4(21.1)$ & \\
\hline 1 & $17(38.6)$ & $9(47.4)$ & \\
\hline 2 & $8(18.2)$ & $4(21.1)$ & \\
\hline 3 & $1(2.3)$ & $2(10.5)$ & \\
\hline 4 & $1(2.3)$ & $0(0.0)$ & \\
\hline NPRS $[n(\%)]$ & & & 0.27 \\
\hline 0 & $14(31.8)$ & $2(10.5)$ & \\
\hline 1 & $10(22.7)$ & $4(21.1)$ & \\
\hline 2 & $14(31.8)$ & $10(52.6)$ & \\
\hline 3 & $6(13.6)$ & $3(15.8)$ & \\
\hline The Barthel index of ADL $[n(\%)]$ & & & 0.57 \\
\hline $50-70$ & $15(34.1)$ & $4(21.1)$ & \\
\hline $75-95$ & $5(11.4)$ & $3(15.8)$ & \\
\hline 100 & $24(54.5)$ & $12(63.2)$ & \\
\hline Severity grade of TG18 $[n(\%)]$ & & & 0.46 \\
\hline I (mild) & $24(54.5)$ & $14(73.3)$ & \\
\hline II (moderate) & $8(18.2)$ & $2(10.5)$ & \\
\hline III (severe) & $12(27.3)$ & $3(15.8)$ & \\
\hline Clinical pathological diagnosis $[n(\%)]$ & & & 0.27 \\
\hline Simple & $53.4(13.0)$ & $49.3(14.3)$ & \\
\hline Phlegmonous & $18(40.9)$ & $12(63.2)$ & \\
\hline Gangrenous & $26(59.1)$ & $7(36.8)$ & \\
\hline Pathological diagnosis $[n(\%)]$ & & & 0.06 \\
\hline Acute cholecystitis & $5(11.4)$ & $7(36.8)$ & \\
\hline Acute on chronic cholecystitis & $21(47.7)$ & $6(31.6)$ & \\
\hline Chronic cholecystitis & $18(40.9)$ & $6(31.6)$ & \\
\hline Mortality $[n(\%)]$ & 0 & 0 & - \\
\hline $\operatorname{ICU}[n(\%)]$ & 0 & 0 & - \\
\hline Conversion rate $[n(\%)]$ & $1(2.3)$ & $0(0.0)$ & - \\
\hline
\end{tabular}


Table 4 (continued)

\begin{tabular}{llll}
\hline Characteristics & $\begin{array}{l}\text { Grade II (moderate) } \\
(n=44)\end{array}$ & $\begin{array}{l}\text { Grade I (mild) } \\
(n=19)\end{array}$ \\
\hline No. patients with complications [ $(\%)]$ & $1(2.3)$ & $0(0.0)$ \\
Operative time (min) [median (IQR)] & $177.0(133.0-220.0)$ & $162.0(125.0-208.5)$ \\
Duration of postoperation hospitalization (days) [median & $6.0(5.0-8.0)$ & $6.0(4.5-6.5)$ & - \\
$\quad$ (IQR)] & & $8.0(5.5-9.0)$ \\
Total hospital length of stay (days) [median (IQR)] & $10.0(8.0-13.0)$ & $8100(6700-9400)$ \\
Cost for surgery (Yuan) [median (IQR)] & $7800(5900-11,000)$ & $30,000(24,300-35,400)$ \\
Total cost of hospitalization (Yuan) [median (IQR)] & $38,900(32,500-45,500)$ & $<.26$ \\
\hline
\end{tabular}

LC Laparoscopic Cholecystectomy, IQR Inter Quartile Range, APACHE IV Acute Physiology and Chronic Health Evaluation IV, MEWS Modified Early Warning Score, CCI Charlson Comorbidity Index, ASA-PS American Society of Anesthesiologists Physical Status Classification, SOFA Sequential Organ Failure Assessment, qSOFA quick Sequential Organ Failure Assessment, SIRS Systemic Inflammatory Response Syndrome, NPRS Numerical Pain Rating Scale, ADL Activities of Daily Living, TG18 Tokyo Guideline 2018, ICU intensive care unit

Bold values are statistically significant difference with alpha of 0.05
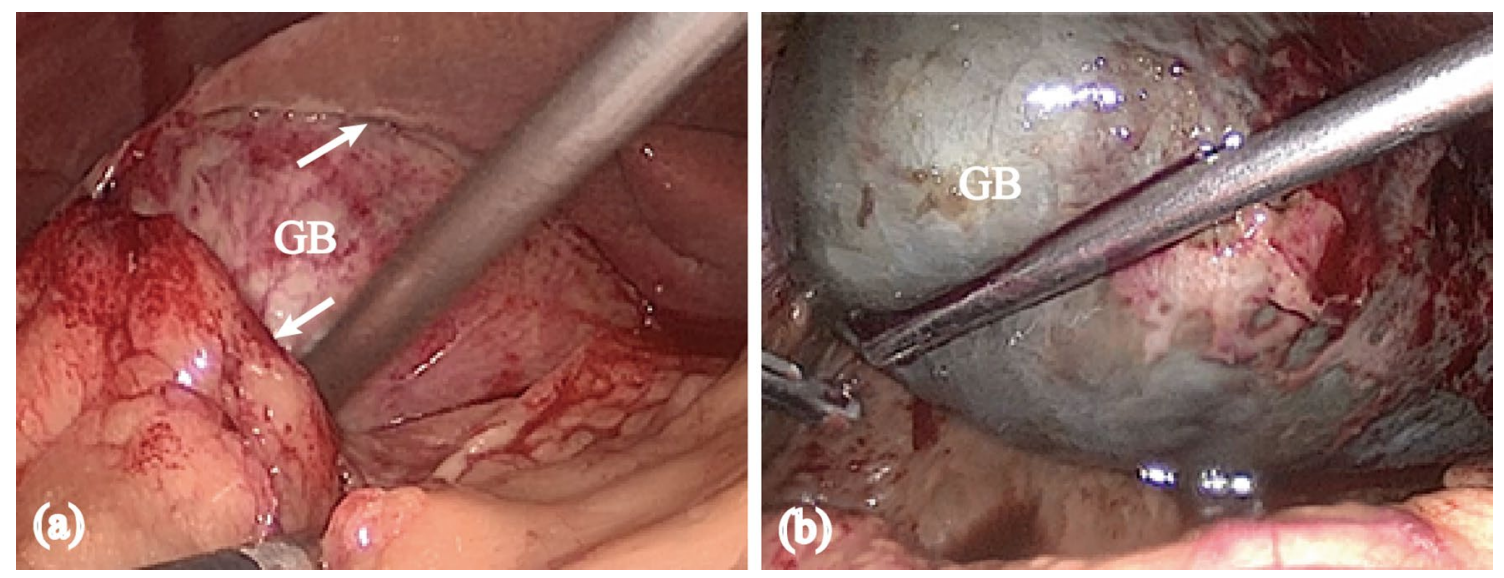

Fig. 4 Difficult cases in clinical practice. A The gallbladder (GB) was tightly adherent with liver and omentum (arrows). B Severe gangrenous GB, which was black and distended

Author contributions $\mathrm{JZ}$ focused on study design and made important modifications to paper. XC focused on data collection, analysis, and draft organization. PC provided the images during the operation. PX, $\mathrm{PH}$ assisted in information collection and participated in data analysis. XC, PC, PX, PH, GZ, KT, GW, XS and JZ approved the final version of the paper.

\section{Funding None.}

\section{Compliance with ethical standards}

Disclosure Xing Cheng, Ping Cheng, Peng Xu, Ping Hu, Gang Zhao, Kaixiong Tao, Guobin Wang, Xiaoming Shuai, and Jinxiang Zhang declare that they have no conflict of interests.

Open Access This article is licensed under a Creative Commons Attribution 4.0 International License, which permits use, sharing, adaptation, distribution and reproduction in any medium or format, as long as you give appropriate credit to the original author(s) and the source, provide a link to the Creative Commons licence, and indicate if changes were made. The images or other third party material in this article are included in the article's Creative Commons licence, unless indicated otherwise in a credit line to the material. If material is not included in the article's Creative Commons licence and your intended use is not permitted by statutory regulation or exceeds the permitted use, you will need to obtain permission directly from the copyright holder. To view a copy of this licence, visit http://creativecommons.org/licenses/by/4.0/.

\section{References}

1. Kimura Y, Takada T, Kawarada Y, Nimura Y, Hirata K, Sekimoto M, Yoshida M, Mayumi T, Wada K, Miura F, Yasuda H, Yamashita Y, Nagino M, Hirota M, Tanaka A, Tsuyuguchi T, Strasberg SM, Gadacz TR (2007) Definitions, pathophysiology, and epidemiology of acute cholangitis and cholecystitis: Tokyo Guidelines. J Hepato-Biliary-Pancreat Surg 14:15-26

2. Beckingham IJ (2001) ABC of diseases of liver, pancreas, and biliary system Gallstone Disease. BMJ 322:91-94 
3. Philipp SR, Miedema BW, Thaler K (2009) Single-incision laparoscopic cholecystectomy using conventional instruments: early experience in comparison with the gold standard. J Am Coll Surg 209:632-637

4. Okamoto K, Suzuki K, Takada T, Strasberg SM, Asbun HJ, Endo I, Iwashita Y, Hibi T, Pitt HA, Umezawa A, Asai K, Han H, Hwang T, Mori Y, Yoon Y, Huang WS, Belli G, Dervenis C, Yokoe M, Kiriyama S, Itoi T, Jagannath P, Garden OJ, Miura F, Nakamura M, Horiguchi A, Wakabayashi G, Cherqui D, de Santibañes E, Shikata S, Noguchi Y, Ukai T, Higuchi R, Wada K, Honda G, Supe AN, Yoshida M, Mayumi T, Gouma DJ, Deziel DJ, Liau K, Chen M, Shibao K, Liu K, Su C, Chan ACW, Yoon D, Choi I, Jonas E, Chen X, Fan ST, Ker C, Giménez ME, Kitano S, Inomata M, Hirata K, Inui K, Sumiyama Y, Yamamoto M (2018) Tokyo Guidelines 2018: flowchart for the management of acute cholecystitis. J Hepato-Biliary-Pancreat Sci 25:55-72

5. Loozen CS, van Santvoort HC, van Duijvendijk P, Besselink MG, Gouma DJ, Nieuwenhuijzen GA, Kelder JC, Donkervoort SC, van Geloven AA, Kruyt PM, Roos D, Kortram K, Kornmann VN, Pronk A, van der Peet DL, Crolla RM, van Ramshorst B, Bollen TL, Boerma D (2018) Laparoscopic cholecystectomy versus percutaneous catheter drainage for acute cholecystitis in high risk patients (CHOCOLATE): multicentre randomised clinical trial. BMJ 363:k3965

6. Wiggins T, Markar SR, Mackenzie H, Jamel S, Askari A, Faiz O, Karamanakos S, Hanna GB (2018) Evolution in the management of acute cholecystitis in the elderly: population-based cohort study. Surg Endosc 32:4078-4086

7. Gurusamy K, Samraj K, Gluud C, Wilson E, Davidson BR (2010) Meta-analysis of randomized controlled trials on the safety and effectiveness of early versus delayed laparoscopic cholecystectomy for acute cholecystitis. Br J Surg 97:141-150

8. Lau H, Lo CY, Patil NG, Yuen WK (2006) Early versus delayedinterval laparoscopic cholecystectomy for acute cholecystitis. Surg Endosc 20:82-87

9. Loozen CS, van Ramshorst B, van Santvoort HC, Boerma D (2018) Acute cholecystitis in elderly patients: A case for early cholecystectomy. J Visc Surg 155:99-103

10. Miura F, Takada T, Strasberg SM, Solomkin JS, Pitt HA, Gouma DJ, Garden OJ, Büchler MW, Yoshida M, Mayumi T, Okamoto K, Gomi H, Kusachi S, Kiriyama S, Yokoe M, Kimura Y, Higuchi R, Yamashita Y, Windsor JA, Tsuyuguchi T, Gabata T, Itoi T, Hata J, Liau K (2013) TG13 flowchart for the management of acute cholangitis and cholecystitis. J Hepato-Biliary-Pancreat Sci 20:47-54

11. Barcelo M, Cruz-Santamaria DM, Alba-Lopez C, Devesa-Medina MJ, Diaz-Rubio M, Rey E (2013) Advantages of early cholecystectomy in clinical practice of a terciary care center. Hepatobiliary Pancreat Dis Int 12:87-93

12. Wu XD, Tian X, Liu MM, Wu L, Zhao S, Zhao L (2015) Metaanalysis comparing early versus delayed laparoscopic cholecystectomy for acute cholecystitis. Br J Surg 102:1302-1313

13. Degrate L, Ciravegna AL, Luperto M, Guaglio M, Garancini M, Maternini M, Giordano L, Romano F, Gianotti L, Uggeri F (2013) Acute cholecystitis: the golden 72-h period is not a strict limit to perform early cholecystectomy. Results from 316 consecutive patients. Langenbeck's Archiv Surg 398:1129-1136

14. Gomes RM, Mehta NT, Varik V, Doctor NH (2013) No 72-hour pathological boundary for safe early laparoscopic cholecystectomy in acute cholecystitis: a clinicopathological study. Ann Gastroenterol 26:340-345

15. Roulin D, Saadi A, Di Mare L, Demartines N, Halkic N (2016) Early versus delayed cholecystectomy for acute cholecystitis, are the 72 hours still the rule? Ann Surg 264:717-722
16. Kawamoto Y, Fujikawa T, Sakamoto Y, Emoto N, Takahashi R, Kawamura Y, Tanaka A (2018) Effect of antithrombic therapy on bleeding complications in patients receiving emergency cholecystectomy for acute cholecystitis. J Hepato-Biliary-Pancreat Sci 25:518-526

17. Saad S, Strassel V, Sauerland S (2013) Randomized clinical trial of single-port, minilaparoscopic and conventional laparoscopic cholecystectomy. Br J Surg 100:339-349

18. Bisgaard T, Klarskov B, Trap R, Kehlet H, Rosenberg J (2002) Microlaparoscopic vs conventional laparoscopic cholecystectomy. Surg Endosc Other Interv Tech 16:458-464

19. Cameron IC, Chadwick C, Phillips J, Johnson AG (2002) Acute cholecystitis-room for improvement? Ann R Coll Surg Engl 84:10-13

20. Ambe PC, Kaptanis S, Papadakis M, Weber SA, Zirngibl H (2015) Cholecystectomy vs. percutaneous cholecystostomy for the management of critically ill patients with acute cholecystitis: a protocol for a systematic review. Syst Rev 4:77

21. Gutt CN, Encke J, Köninger J, Harnoss J, Weigand K, Kipfmüller K, Schunter O, Götze T, Golling MT, Menges M, Klar E, Feilhauer K, Zoller WG, Ridwelski K, Ackmann S, Baron A, Schön MR, Seitz HK, Daniel D, Stremmel W, Büchler MW (2013) Acute cholecystitis. Ann Surg 258:385-393

22. de Mestral C, Rotstein OD, Laupacis A, Hoch JS, Zagorski B, Alali AS, Nathens AB (2014) Comparative operative outcomes of early and delayed cholecystectomy for acute cholecystitis. Ann Surg 259:10-15

23. Blythe J, Herrmann E, Faust D, Falk S, Edwards-Lehr T, Stockhausen F, Hanisch E, Buia A (2018) Acute cholecystitis \&ndash; a cohort study in a real-world clinical setting (REWO study, NCT02796443). Pragmat Obs Res 9:69-75

24. Meng FY, Tsao MZ, Huang ML, Huang HW (2012) Laparoscopic cholecystectomy techniques with special care treatment in acute cholecystitis patients regardless of operation timing. Hepatogastroenterology 59:1006-1009

25. Merriam LT, Kanaan SA, Dawes LG, Angelos P, Prystowsky JB, Rege RV, Joehl RJ (1999) Gangrenous cholecystitis: analysis of risk factors and experience with laparoscopic cholecystectomy. Surgery 126:680-685 discussion 685-6

26. Wilson AK, Kozol RA, Salwen WA, Manov LJ, Tennenberg SD (1994) Gangrenous cholecystitis in an urban VA hospital. J Surg Res 56:402-404

27. Bourikian S, Anand RJ, Aboutanos M, Wolfe LG, Ferrada P (2015) Risk factors for acute gangrenous cholecystitis in emergency general surgery patients. Am J Surg 210:730-733

28. Habib FA, Kolachalam RB, Khilnani R, Preventza O, Mittal VK (2001) Role of laparoscopic cholecystectomy in the management of gangrenous cholecystitis. Am J Surg 181:71-75

29. Oymaci E, Ucar AD, Yakan S, Carti EB, Coskun A, Erkan N, Yildirim M (2014) Determination of optimal operation time for the management of acute cholecystitis: a clinical trial. Gastroenterol Rev 3:147-152

30. Hadad SM, Vaidya JS, Baker L, Koh HC, Heron TP, Hussain K, Thompson AM (2007) Delay from symptom onset increases the conversion rate in laparoscopic cholecystectomy for acute cholecystitis. World J Surg 31:1298-1301 discussion 1302-3

Publisher's Note Springer Nature remains neutral with regard to jurisdictional claims in published maps and institutional affiliations. 